\title{
Simulacros. Una manera de pervivir la teatralidad
}

Simulacros. A way to survive the theAtricality

\author{
Alejandro Flores Solís* \\ Blanca Lilia Hernández Reyes*
}

Resumen: La manera como se percibe en México el sabor, el olor y los componentes visuales de la fiesta sucede mediante la transmisión generacional de cada celebración. La conmemoración de la Independencia de México tiene una particular modalidad de expresión: el simulacro, una forma de teatralidad que involucra a miles de participantes en varios municipios de la zona sur del Estado de México, como Coatepec Harinas, Tecomatlán, Malinalco y Tejupilco. Su arraigo entre las comunidades se debe a la antigüedad y preservación del fenómeno. Dentro de dicho marco, este estudio se concentra en los simulacros efectuados el 15 y 16 de septiembre en Ixtapan de la Sal, y el 26 y 27 del mismo mes en Tonatico, días en los que la rutina se detiene y cede el paso a un tiempo-espacio propicio para el juego y la representación como agentes de transformación y cohesión comunitarios. Palabras clave: teatro popular; historia nacional; memoria colectiva; identidad nacional; actividad sociocultural; costumbres y tradiciones; folclor; festividad; máscara

* Universidad Autónoma del Estado de México

Correo-e: jando37@gmail.com

Recibido: 9 de noviembre de 2020 Aprobado: 7 de junio de 2021

\begin{abstract}
The way the party's taste, smell and visual components are perceived in Mexico happens through the generational transmission of each celebration. The commemoration of the Independence of Mexico has a particular mode of expression: the simulacrum, a form of theatricality that involves thousands of participants in various municipalities in the southern part of the State of Mexico, such as Coatepec Harinas, Tecomatlán, Malinalco and Tejupilco. Its roots among the communities is due to the antiquity and preservation of the phenomenon. Within this framework, this study focuses on the drills carried out on September 15 and 16 in Ixtapan de la Sal, and on September 26 and 27 in Tonatico, days in which the routine stops and gives way to a time-space conducive to play and representation as agents of community transformation and cohesion.
\end{abstract}

Keywords: popular theatre; national history; collective memory; national identity; socio-cultural activities; customs and traditions; folklore; feasts; masks 
Lo que nos es familiar se convierte en invisible: hacer teatro, al contrario, ilumina el escenario de nuestra vida cotidiana. Augusto Boal

\section{INTRODUCCIÓN}

La presente reflexión se concentra en el abordaje de las teatralidades que se efectúan en el marco de las festividades cívicas de carácter popular denominadas por los propios participantes 'simulacros'. Estos se realizan de manera anual durante dos días en los cuales se observan actos representacionales-performativos determinados por fuerzas que los instalan en el abismo del límite, dado el desborde frenético con que se expresan, funcionan y generan cambios en aras de modificar el significado de la vida, reconfigurando el ser social.

Conviene preguntarse si la experiencia liminal en estas teatralidades que se manifiestan en diversas poblaciones del sur del Estado de México, en el marco festivo de la celebración anual de la Independencia de México, llamada Fiestas Patrias, establece espacios de libertad y justicia. Dado el marco de referencia escénico-festivo surge el interés por estudiar la transfiguración social que allí acontece. Si bien el presente estudio se concentra en los municipios de Ixtapan de la Sal y Tonatico, no se resta importancia a fenómenos similares en otras poblaciones, como Chalma, Coatepec Harinas, Tecomatlán, Malinalco, Tejupilco y Palmar Chico, por mencionar algunas.

Antes de examinar las características particulares de estas dramatizaciones, partimos de ideas ordenadoras sobre la teatralidad, la estructura del simulacro y su inexorable sentido lúdico-festivo. Del mismo modo, planteamos el nivel de significación de los acontecimientos en tanto representaciones culturales. A continuación, se proporciona una descripción de los simulacrosteatralidades con la finalidad de comprender su estructura como eventos socioculturales para, entonces, abordar los planteamientos de análisis vinculados con lo escénico y, así, proponer conclusiones.

Fundamentalmente, el punto de referencia analítica de nuestra reflexión es el campo de las representaciones escénicas, en particular las teatrales, sin descartar las orientaciones que brindan estudios realizados con otros enfoques, ya sean de tipo social, antropológico e histórico, por lo tanto, el objetivo principal radica en examinar dichas celebraciones desde una perspectiva interdisciplinar que se configura con los elementos de todo acto representacional, es decir, la presencia de un observador y un observado en un tiempoespacio extraordinario.

\section{PRIMER ACTO: LA TEATRALIDAD}

Hablar de teatralidad ${ }^{1}$ implica examinar sus componentes basándonos en expresiones binarias, como tiempo-espacio y acción-ficción, en consecuencia, aflora la esencia de todo acto escénico-representacional que se expresa en la condensación del pensamiento desde los sujetos, encargados de estructurar el universo de significados y procesos comunicativos que se desprenden de toda acción puesta en ficción.

1 La teatralidad es una especificidad de lo teatral, "un acto convivial y representacional (performativo) que se estructura a través de un conjunto de dramas-acciones, de una totalidad mimética enunciante, de hechos significativos que se gestan en un tiempo y espacio ficcional y permiten la transmisión de discursos que configuran imaginarios sociales y sistemas de códigos de comunicación a través del conjunto de percepciones, de acciones lúdicas, visuales, sonoras y significativas que se manifiestan en la autorrepresentación del hombre social, en la variedad de roles, máscaras-personajes que los involucrados pueden desempeñar. De ahí que se manifieste como un constructo sociocultural, un espesor de signos y sensaciones, involucra ceremonias y rituales, caracterizados de forma particular porque necesitan de un espectador activo, un público que personifique su propia existencia" (Flores Solís, 2016: 39). 
Tiempo y espacio se aprecian como construcciones en las cuales se condensan potencias de significado. El espacio es el lugar en donde se manifiestan las acciones que realizan los sujetos; es real y ficcional, y forma estructuras simbolizadas, un escaparate para observar cómo los sujetos recrean a otros. Por tal motivo, mediante los personajes se generan y sintetizan abstracciones cuyo basamento es la realidad misma. Tiempo y espacio otorgan vida a lo escénico, adquieren sentido mediante las evoluciones gestuales y así producen interacciones reales y simbólicas.

El tiempo escénico se funde con el tiempo real desde el momento en que se impone como un soporte del argumento, articula discursos y reconstituye la realidad. Su referente es la dinámica de la representación, es decir, dos sujetos reunidos en presencia física en un tiempo y un espacio específicos. Por lo mismo, es indispensable establecer un orden aplicable a los tiempos (pasado, presente) que concurren en todo acto representacional, no obstante, éstos se reconfiguran simbólicamente por el drama sin manifestarse de manera lineal si no de forma progresiva, permitiendo así la reconstrucción cargada de simbolismo desde la óptica del tiempo escénico.

Por su parte, la acción y la ficción comulgan como elementos desde los cuales los sujetos-actores se mueven, relacionan y establecen formas de interacción reales y simbólicas que se articulan en los discursos como un complejo de simulaciones y representaciones, por ende, interpretan la realidad circundante y el contexto experiencial donde se desarrolla el sujeto; a final de cuentas se trata de sistematizaciones ficcionales.

De esta manera, las teatralidades contienen elementos temporales que suceden en espacios reconstruidos de manera simbólica y se observa en ellas un conjunto de interacciones alteradas a condición de la representación. Como resultado, pasan a formar parte del hecho escénico, ya que facilitan la producción de acontecimientos imaginarios (ficticios), así los conflictos humanos y su resolución promueven la expectación de quien mira el acontecimiento (Tovar, 2006).

Esta serie de distintivos de las teatralidades deja al descubierto un conjunto de interacciones entre los sujetos y construye el entramando de universos experienciales desde los que se acciona en y con la realidad circundante. Sin duda alguna, es necesario recapacitar sobre cada conjunto de actos conviviales y representacionales (performativos) manifiestos cada vez que sucede la representación, porque necesitan de un espectador activo que encarne su propia existencia.

Por ello, coincidimos con el investigador teatral Jorge Dubatti cuando menciona que:

El teatro acontece históricamente en las coor-
denadas espaciotemporales de la empiria
cotidiana, pero su medio expresivo son las
acciones corporales, físicas y físico-verbales,
generadas por alguien con su cuerpo ante otro
que observa (percibe, no sólo mira) esas accio-
nes en presencia de él. Cuerpo y percepción. El
teatro es acontecimiento corporal empírico en
acto, hecho histórico de la vida que puede ates-
tiguar quien lo observa ( $2007: 34)$.

Es decir, se apertura el diálogo con el espectador, quien es el testigo y protagonista de la teatralidad. En palabras de Dubatti, esta última no puede generarse sin que se articule la expectación y, por ende, las formas convivales que requiere todo acto escénico-representacional. Por ello, es necesaria la presencia de los sujetos, protagonistas de su propia realidad.

Otro rasgo de las teatralidades tiene que ver con la manera que tienen de transparentarse como acontecimientos de la cultura al entablar relaciones e interacciones al interior y exterior para conectarse de manera directa con el contexto y la realidad, pues:

La base de la teatralidad debe buscarse en las estructuras conviviales. Sin convivio -reunión 
de dos o más hombres, encuentro de presencias en una encrucijada espacio-temporal cotidiana- no hay teatro, de allí que podamos reconocer en él el principio —en el doble sentido de fundamento y punto de partida lógico temporal — de la teatralidad (Dubatti, 2007: 43).

Debe suponerse que el sujeto es quien recrea las realidades desde la interacción con los otros y el entorno, tanto real como simbolizado o ficcional, en el que tiene participación. Sin embargo, un denominador común en las teatralidades motivo del presente estudio es su escenificación compleja, donde predominan la gestualidad corporal, el juego vocal y la configuración espaciotemporal abarcadora de toda una población, para adentrarse en un mundo alterno mediante el artificio de la ritualidad como punto de convergencia entre lo simbólico y el significado de la vida en colectividad. La teatralidad permite la sátira, el humor, utiliza metáforas verbalizadas, ironiza, aprende de la historia y deconstruye el paradigma oficial de la Independencia de México. En cada representación, el hecho se rehace una y otra vez a semejanza del juego, de manera que estamos frente a un acto inacabado o en el plano de la indecibilidad.

Dichas teatralidades, como parte de su dinámica, permiten la elaboración de procesos identitarios fundamentales para la propia comunidad que los genera, además de convertirse en ejes culturales que legitiman procesos de cohesión grupal (Alcántara Mejía, 2002); en definitiva, funcionan como actos colectivos en los que se manifiestan conflictos cuya resolución se logra hasta el momento de la escenificación. Por ello, adquieren el sentido de representación de la cultura, donde el sujeto participante se reconstituye a partir de la interacción social. Las teatralidades subliman experiencias catárticas relacionadas con la liberación del ser, además, son un medio para simbolizar y modificar las relaciones entre individuos, los sentimientos de comunidad, así como los procesos comunicativos y la organización respecto a las circunstancias en que se vive, son una afirmación cultural que va más allá de las realidades específicas y momentáneas colectivas.

Considerando lo anterior, se tiene como resultado que las teatralidades se reconocen como 'un teatro sin texto', un discurso en el que se pondera la construcción y percepción visual de la realidad, como señala Arana Grajales (2007). Mediante la convención de signos propios, apropiados y reconfigurados, una conducta se vuelve teatral en el momento que es interpretada por otros. Esto lo confirma Néstor García Canclini (1994) cuando menciona que la teatralidad social radica en los modos de representación en los productos culturales.

Podemos agregar la forma en cómo se percibe el universo de las simulaciones. Las acciones que son parte de la realidad no se representan mediante actos escénicos reconfigurados o cargados de una multiplicidad de significados, pues forman parte del mundo experiencial y contextual de los sujetos para construir y deconstruir permanentemente su praxis.

De forma simultánea a esta caracterización de la teatralidad que condensa la generación del acontecimiento, éste puede tener dos orientaciones interpretativas. La primera, como hecho escénico en sí, es decir, como la interacción entre los actores desde el momento en que se genera el acto convival. La segunda tiene que ver con los procesos y el orden manifiestos en las acciones que realizan los actores personajes en el tiempoespacio representacional, como afirma Žižek:

Acontecimiento es un cambio de planteamiento a través del cual percibimos el mundo y nos relacionamos con él. En ocasiones, dicho planteamiento puede presentarse directamente como una ficción que no obstante nos permite decir la verdad de un modo indirecto (2014: 24). 
Es decir, se presencia una serie de actos, acciones simuladas sobre algo que se admite o niega, susceptible de crítica, que cuestiona lo que sucede en la realidad desde la representación y, sobre todo, permite hacer cambios reales y simbólicos del contexto circundante con la intención de buscar la armonía, aunque eso genere crisis en el orden existente.

El valor de representación sociocultural adquiere entonces matices importantes al provocar estallidos y rompimientos al interior de la estructura social, aunque sean representacionales, en donde la subjetividad inunda el escenario y la teatralidad condensa un espesor de signos incluso contradictorios, así lo real se revela a partir de lo escénico.

Si bien esta caracterización de las teatralidades permite comprender el universo desde el cual se mueven y articulan en un tiempo-espacio escénico, el conjunto de acciones dotadas de ficción posibilita relacionar esta categoría con el objeto de estudio del presente documento: los simulacros con motivo de la festividad cívica de la Independencia de México, de manera específica, los realizados en Ixtapan de la Sal y Tonatico.

Segundo acto: la fiesta del Simulacro

Venimos desde Chihuahua con don Vicente Guerrero, a darle en la madre a España y tumbarle el gallinero... Coplas del contingente de Apaches Ixtapan de la Sal

Ixtapan de la Sal y Tonatico son dos cabeceras municipales que se encuentran en el sur del Estado de México y forman parte importante de la fisonomía geográfica por su producción agropecuaria. Se ubican en la parte suroriente del Nevado de Toluca, cuentan con balnearios y aguas termales, lo que les ha permitido crecer como poblaciones con atractivos turísticos (Vázquez Illana, 1992a).

Cada año, en estos lugares se realiza la celebración de la Independencia de México, conocida también como Fiestas Patrias. Los propios pobladores denominan 'simulacro' (Pérez Domínguez, 2011) al acto de representar este acontecimiento, una festividad de carácter cívico, pero que condensa en sus formas sincretismos que promueven la conservación de imaginarios sociohistóricos importantes para la región. En el caso de Tonatico, el historiador García Castro menciona lo siguiente:

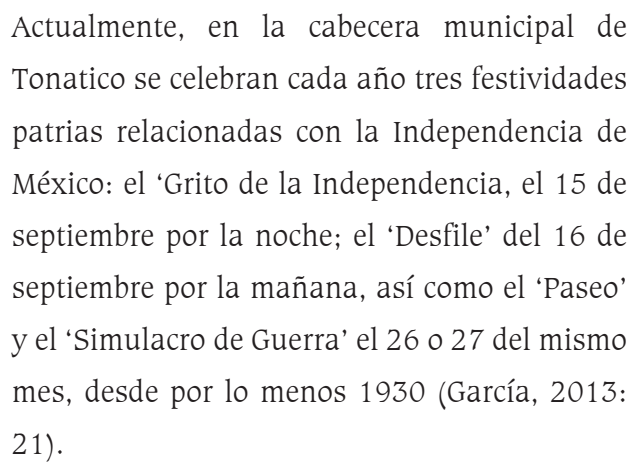

En Ixtapan de la Sal solamente se llevan a cabo dos festividades, el 15 y 16 de septiembre, sin embargo, mantienen con Tonatico similitudes en las estructuras desde las cuales realizan los simulacros, pues en ambos lugares las formas conviviales involucran a la mayoría de los habitantes, incluso el retorno temporal de la población migrante en estas fechas es importante.

- La configuración de las teatralidades se vive en tres momentos importantes:

- Antes: preparativos desde los cuales se gesta la celebración, permiten observar las formas de organización que mantiene cada municipio.

- Durante: en cada acto y segmento de la festividad se suman formas y estructuras escénico-representacionales, en donde el tiempo-espacio, la acción-ficción y las formas conviviales son observables. 
- Después: retorno a la cotidianidad, en este sentido, se renuevan elementos estructurales e identitarios para la comunidad.

Ahora bien, se observan transfiguraciones que denotan la inclusión de nuevos elementos y, a su vez, mantienen formas tradicionales que pasan de generación en generación. Se dice que la fiesta comenzó a realizarse hacia 1859, cuando un grupo de ciudadanos decidió homenajear a los hombres caídos en la guerra de Independencia y posteriores conflictos bélicos que aún no habían cesado en buena parte del territorio nacional, fue así como se presentó una danza nombrada de los Apaches en la plaza de Tonatico, una versión primaria de lo que ahora se conoce como el simulacro. Algunas fotografías de Cornelio Mendoza, fechadas entre 1930 y 1942 (Arizmendi, 1999), prueban que esta danza se originó en esa localidad, sin embargo, no se tienen fuentes contundentes que testifiquen que se haya presentado desde 1859. Durante el movimiento revolucionario de 1910 se interrumpió la celebración durante algunos años y en 1930 se acordó que el 26 y 27 de septiembre serían las fechas para festejar la Independencia de México en Tonatico, mientras que en Ixtapan se celebra el 15 y 16. ${ }^{2}$ En el caso de Tonatico, Pérez Domínguez (2011) menciona que el cambio de fechas, de acuerdo con los datos aportados por Óscar Vázquez (1992b), fue debido a la dificultad para conseguir bandas de música el 15 y 16. Desde 1945 se modificó el calendario de la celebración, información que la misma población conserva como parte de su acervo histórico y comparte mediante la tradición oral. ${ }^{3}$

El análisis nos lleva a proponer que la teatralidad es el lenguaje idóneo mediante el cual los habitantes descubren un espacio de expresión plural donde pueden manifestar lúdicamente su propio concepto de la Independencia, trazando un cruce de elementos rituales, festivos

2 Trabajo de campo, 2019.

3 Trabajo de campo, 2019. y carnavalescos. Dichas prácticas socioculturales generan la producción de imaginarios. Gracias a la repetición, el simulacro guarda reminiscencias del ritual, porque reestablece el orden en la dimensión de lo humano y el imaginario colectivo.

En el caso de ambas poblaciones, desde la tarde del 15 de septiembre las tropas recorren las calles rumbo a la iglesia donde se oficia una misa para recibir la bendición y llevar a buen término el acto (Imágenes 1 y 2). Una vez concluida la ceremonia, quienes personifican a los insurgentes se dirigen al balcón del Palacio Municipal para escenificar el Grito de Independencia — pasaje de la historia donde Miguel Hidalgo y Costilla, un sacerdote criollo que radicó en el pueblo de Dolores, Hidalgo, convocó a la muchedumbre para levantarse en armas la noche del 15 de septiembre de 1810 - . Delante de miles de espectadores se desata la euforia con las consignas 'Viva México', 'Vivan los héroes que nos dieron patria y libertad', 'Viva Ixtapan', 'Viva Tonatico'. Los fuegos pirotécnicos y la masa tricolor dan la sensación de un lienzo viviente, lleno de rostros y voces que se parecen y anhelan lo mismo, ¿libertad? ${ }^{4}$

\section{Imagen 1. Altar de misa insurgente, Ixtapan de} LA SAL

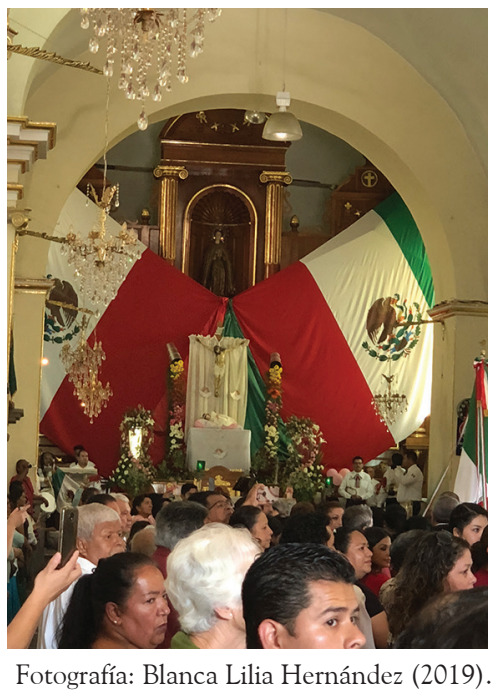

4 Trabajo de campo, 2019. 
Imagen 2. Tropa de insurgentes en misa, Ixtapan DE LA SAL

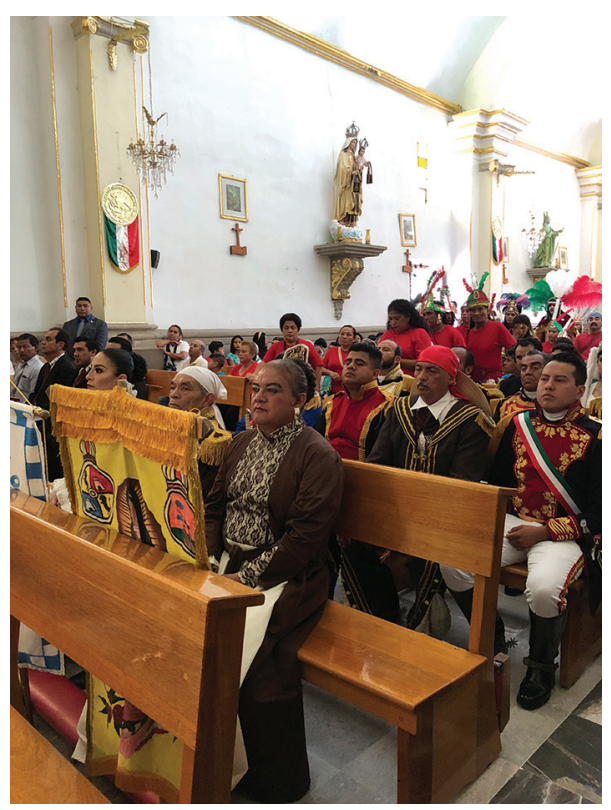

Fotografía: Blanca Lilia Hernández (2019).

Al terminar la noche del 15 de septiembre concluye la primera etapa del simulacro. Al día siguiente se simula la guerra entre españoles, el ejército insurgente y el pueblo. Durante el transcurso de la mañana y hasta entrada la tarde, se realiza un desfile integrado por las tropas de costeños, guarines, insurgentes, apaches, españoles y, por supuesto, los pobladores. El recorrido constituye un espacio para la creación de imaginarios, el tiempo cotidiano se transforma en tiempo de fiesta cuando se caminan las calles/escenario revestidas por música, baile, coplas, detonaciones de mosquetes y alcohol (Imagen 3).

\section{Imagen 3. Batalla o entrada, Tonatico}

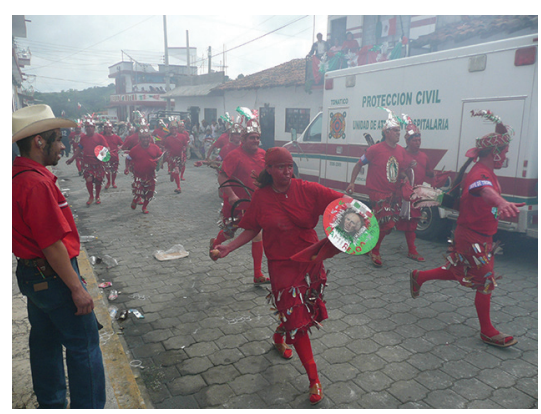

Fotografía: Blanca Lilia Hernández (2019).
Después de casi cuatro horas, el simulacro se suspende, los participantes descansan y comparten alimentos, ya sea en familia o con los integrantes de cada tropa. Pasadas dos horas, la teatralidad se reanuda, ahora en un escenario nombrado 'gallinero', una recreación precaria o ruinosa de la Alhóndiga de Granaditas -edificio ubicado en la capital del estado de Guanajuato, que funcionaba como almacén de granos y era administrado por los españoles ricos de la época —; históricamente, la toma de este recinto significó la primera conquista del pueblo. ${ }^{5}$

La alhóndiga del simulacro consiste en una escenografía hecha a base de tablones de 15 metros de altura aproximadamente. Quien presencia el evento se deja tocar por el sabor de la bebida popular — el coyote-, y se intimida o emociona ante las detonaciones de mosquetes que acorralan al bando contrario. La presencia de fluidos corporales (orina, sudor y sangre) es una sacudida de la somnolencia provocada por la atmósfera turbia que dejan las detonaciones de pólvora. El universo de color del simulacro está impregnado por el rojo, el negro, el blanco y el verde. La batalla o guerra representa la rebelión de costeños, guarines e insurgentes contra los españoles, son los momentos más violentos, eufóricos-límite del simulacro, en los que lo real se fusiona con lo ficcional. Después de horas de lucha, los asistentes celebran hasta que la energía les es insuficiente, en el éxtasis destruyen el escenario y lloran la muerte de Miguel Hidalgo. ${ }^{6}$

Los participantes son gente común: campesinos, albañiles, comerciantes, niños, mujeres solteras y casadas, en general puede participar todo aquel que se inicia en el simulacro y desea honrar a su pueblo, a su país y, además, divertirse. Se reconoce una estructura organizacional constituida por la sociedad civil y autoridades de gobierno. La primera está constituida por los líderes de las tropas, incluyendo a los residentes de

5 Trabajo de campo, 2019.

6 Trabajo de campo, 2019. 
Waukegan, Illinois, quienes viajan especialmente en estas fechas a sus lugares de origen para vivir la experiencia (Mora y Sandoval, 2010).

Ahora bien, para comprender el universo espectacular de las tropas iniciaremos por la más emblemática: los apaches. Su atuendo se compone de un faldón rojo del que cuelgan cuentas de lámina para evocar la riqueza minera que existió en la región, éstas, con el movimiento, hacen un ruido semejante al de una sonaja que apoya el ritmo del baile. Además, portan camiseta y medias rojas, huaraches, penacho y machete. Los hombres usan peluca de cabello largo y negro, carcaj con flechas, venablo y escudo; las mujeres, una suntuosa capa de terciopelo rojo, adornada con aplicaciones de lentejuela e imágenes de la Virgen de Guadalupe, flores y el escudo nacional (Imagen 4).

Imagen 4. Tropas apaches, Tonatico.

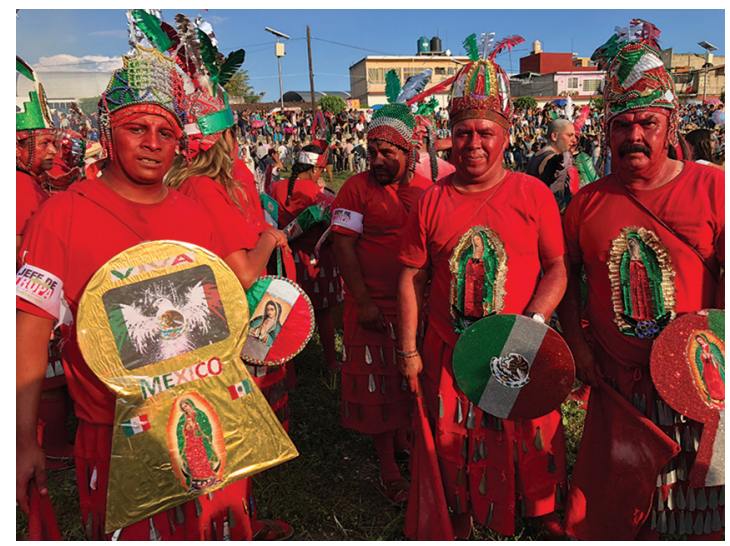

Fotografía: Blanca Lilia Hernández (2019).

Los costeños necesitan cubrir varios requisitos, entre los que destacan tener experiencia en la detonación de armas de fuego, contar con el permiso de la Secretaría de la Defensa Nacional para hacer uso de pólvora y mosquete, y portar el vestuario, consistente en pantalón y camisa negra con flequillos tricolores, botas, sombrero 'costeño' de ala ancha de entre 1 y 1.20 m de diámetro con motivos patrios, personajes y pasajes históricos que se decoran con diamantina. Las mujeres usan también sombrero y falda larga con adornos de lentejuela de la Virgen de Guadalupe, el escudo y la bandera nacional. Todos se maquillan el rostro de negro. Tanto el nombre de la tropa como su caracterización evocan a los afroamericanos que llegaron a esas localidades, producto de la migración desde las costas de Oaxaca y Guerrero (Imagen 5). ${ }^{7}$

\section{Imagen 5. Mujer de la tropa de costeños,} TONATICO

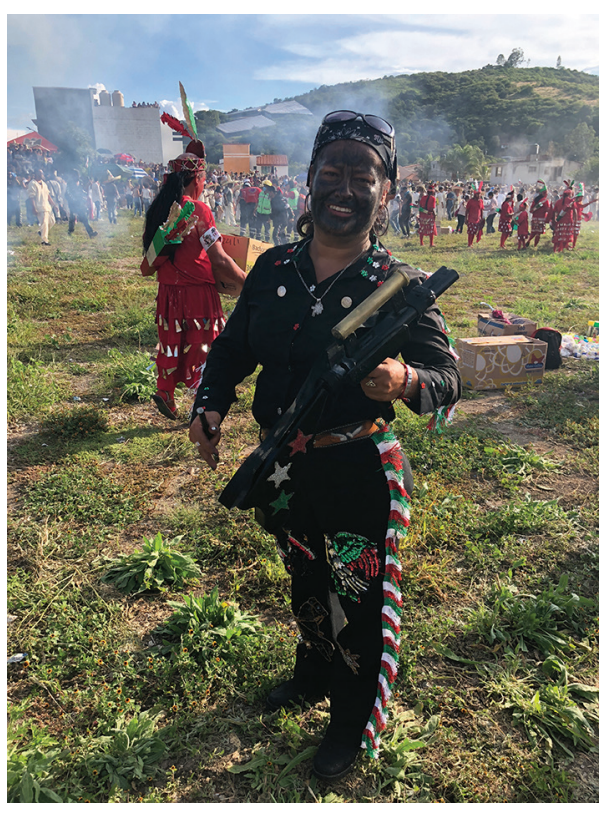

Fotografía: Blanca Lilia Hernández (2019).

Los guarines lucen una indumentaria de manta (calzón y camisa), sombrero de paja y huaraches. La mayoría porta una bandera de México. En Ixtapan de la Sal, los integrantes de esta tropa usan pantalón de peto semejante al de un maquinista de ferrocarril, hecho de manta y decorado con alguna imagen del escudo y bandera nacional. En ambos municipios, los guarines representan el mestizaje, en tono de farsa se teatraliza una versión ruinosa del campesino en cuanto a la ropa, no así en su carácter, que desborda alegría, euforia, y expresa chistes verbales y corporales (Imagen 6).

7 Trabajo de campo, 2019. 
Imagen 6. SátiRa de la tropa de guarines, TONATICO

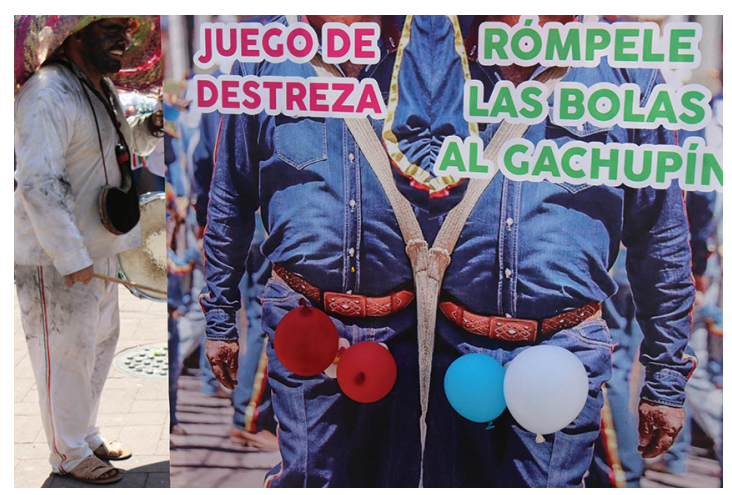

Fotografía: Blanca Lilia Hernández (2019).

Con respecto a los españoles o gachupines, la vestimenta en Ixtapan de la Sal consiste en una casaca estilo militar del siglo XIX azul claro con franjas amarillas y rojas en los costados de las mangas y el pantalón, gorra de palma forrada de la misma tela que la ropa y una bandera hecha con lienzos rojo y amarillo sin escudo para emular la bandera española. En Tonatico, los gachupines tienen otro código de vestimenta, compuesto por camisa y pantalón de mezclilla azul oscuro con franjas rojas y amarillas en los costados, quepí con adornos dorados y azules, botas con casquillos para que sus pasos y marcha tengan sonoridad, y puro, de manera que la presencia de la tropa se enriquece con elementos sensoriales visuales, auditivos y olfativos (Imagen 7).

\section{Imagen 7. Tropa de españoles, Tonatico}

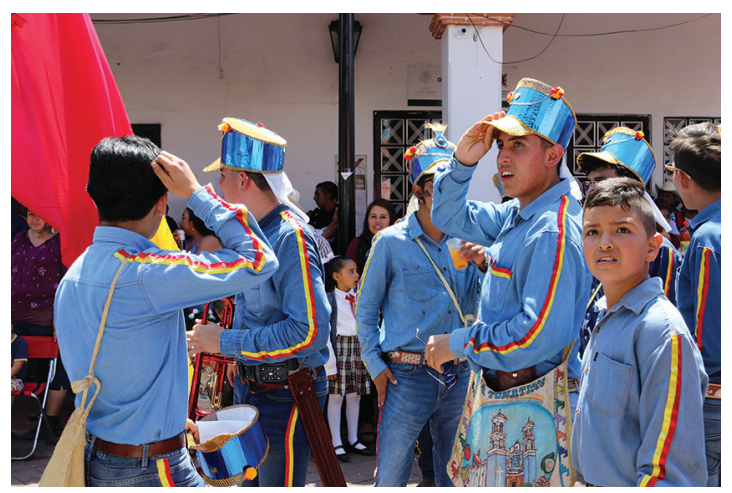

Fotografía: Blanca Lilia Hernández (2019).
Los insurgentes o héroes de la Independencia, Josefa Ortiz de Domínguez, Miguel Hidalgo, Ignacio Allende, José María Morelos y Pavón, Vicente Guerrero, Leona Vicario y José Mariano Jiménez, visten a la usanza del ejército mexicano del siglo XIX, con pantalón blanco, casaca azul con detalles en rojo, botas y sombrero según la jerarquía militar (Imagen 8). ${ }^{8}$

\section{Imagen 8. Entrada de insurgentes, Tonatico}

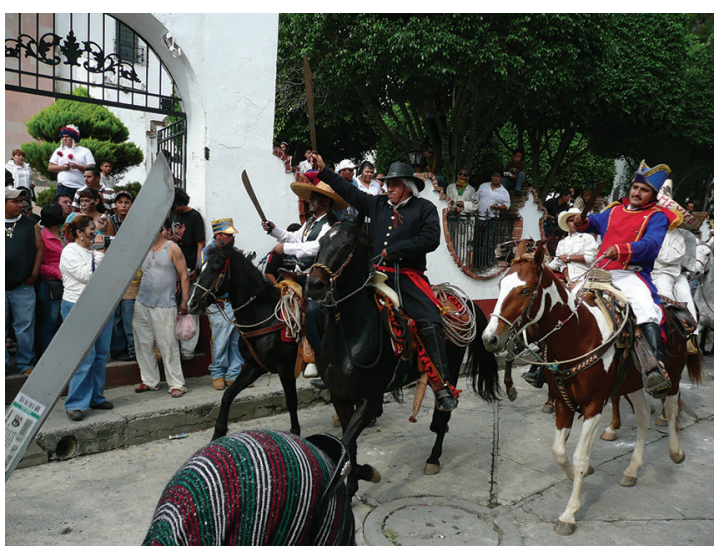

Fotografía: Alejandro Flores S. (2012).

Las adelitas forman un contingente que sólo cuentan con presencia en Ixtapan de la Sal. Según el testimonio del profesor Miguel Torres, actual líder de la tropa insurgente con más de 35 años de participación en el simulacro, 15 años atrás, durante el desfile, empezaron a filtrase hombres que se disfrazaban de mujeres en un sentido grotesco, con absoluta intención de travestismo carente del propósito conmemorativo de la Independencia, por lo tanto, el comité organizador reguló dicha participación mediante una definición específica: 'las adelitas', que portan un atuendo inspirado en las revolucionarias para exaltar los valores del simulacro: honra a la patria y celebración en comunidad (Imagen 9).

8 Trabajo de campo, 2019. 
Imagen 9. Una Adelita, Ixtapan de la Sal

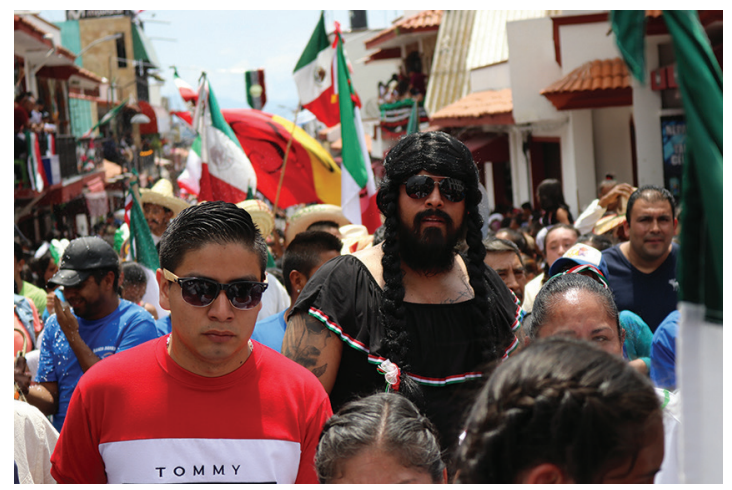

Fotografía: Blanca Lilia Hernández (2019).

\section{TERCER ACTO: EL FENÓMENO SOCIOCULTURAL}

Como tienen a bien nombrar los participantes, los simulacros revelan cualidades que los emparentan con el acontecimiento a partir de los supuestos lacanianos de lo real, lo simbólico e imaginario (Alatriste Tobilla, Bernal Gómez y Encastín Cruz, 2010), es decir, presentan una especie de ruptura con un mensaje político ambivalente. De la misma forma, Slavoj Žižek describe el acontecimiento como "un cambio de planteamiento a través del cual percibimos el mundo y nos relacionamos con él. En ocasiones, este precepto puede presentarse directamente como una ficción que no obstante nos permite decir la verdad de un modo indirecto" (2014: 24).

En este sentido, la teatralidad-acontecimiento de los simulacros abre un debate sobre la sustancia ficcional presente en la representación y presentación (Dubatti, 2007) para mostrar un tipo de realidad a la que se aspira y, de forma antagónica, el rompimiento con aquello que se niega a fin de crear la praxis-acción del acontecimiento convivial. ${ }^{9}$ Es un encuentro del hombre con

9 Concepto formulado por Jorge Dubatti, quien afirma que la base del teatro se constituye por "tres sub-acontecimientos relacionados: el convivio, la poiesis y la expectación” (2010: $34)$. De allí que convivio o acontecimiento convivial refiere la reunión del cuerpo entre artistas y espectadores sin la presencia de la tecnología, en un determinando tiempo y espacio cotidiano, como la sala, la calle, un bar, en tiem- él mismo, reflexión permanente sobre el contexto en el que convive, se relaciona y dibuja como un ente relacional; observación de cómo se resignifica de manera permanente el entorno que le rodea para al final socializar y constituir su presencia sociocrítica. Es decir, el material del cual se alimentan las representaciones es, ante todo, la realidad misma. El contexto marca la pauta y reconoce todo aquello que se quiere revelar, pero al mismo tiempo se muestra como algo renovado. En este ejercicio, el convivio se manifiesta en la forma de un acontecimiento que reúne a los sujetos como cuerpos presentes, en confluencia socioespacial cronotópica desde el conjunto de actos teatralizados.

El juego se complejiza al entrelazar aquello que se representa con el conjunto de acciones reales y no reales, al mismo tiempo que se multiplican los actos recíprocos continuos y la suma de elementos nuevos en cada representación. Desde esta perspectiva, el diálogo se manifiesta como necesidad comunicativa inherente a la teatralidad.

Si bien el simulacro sigue alentando la esperanza del hombre de desprenderse de la crueldad para recuperar un discurso fundado en el afecto mágico/sagrado, se abre también un horizonte para estudiar la función sociocultural de una teatralidad inquietante que apuesta por la exaltación de un espíritu libre ávido de ser observado, pese a su naturaleza violenta y desbordante.

En las poblaciones motivo de nuestro interés, aparentemente el simulacro se originó con una finalidad cívico-estratégica de promover en la niñez y la juventud las nociones de libertad, identidad y pertenencia. Con el paso del tiempo,

\footnotetext{
po presente. A diferencia del cine, la televisión y la radio, demanda la presencia física de los artistas, los técnicos y los espectadores. Así, el teatro es el arte aurático, pues, sostiene el filósofo argentino, los seres humanos no somos los mismos en reunión, ya que se establecen vínculos y afectaciones conviviales, en ocasiones no percibidos. En este acto se "multiplica la actividad de dar y recibir a partir del encuentro, diálogo y mutua estimulación, por eso se le vincula al acontecimiento de la compañía (del latín cum panis, compañero, el que comparte el pan)" (Dubatti, 2010: 34).
} 
este acto ha pasado a convertirse en una práctica cultural, de manera que la comunidad $-\mathrm{y}$ no la autoridad-, es la que diseña, aplica y regula la totalidad del evento. Su carácter autónomo lo sitúa como un fenómeno táctico, pues mediante la repetición anual se abre un espacio de libertad para vivir experiencias de convivencia y confrontación entre los miembros, un acto necesario para la renovación de ciclos y reinvención del mundo.

Nombrado así por los habitantes de las comunidades, el hecho 'simula' funcionar como instrumento político porque hace visibles prácticas sociales establecidas por el Estado, sin embargo, son los involucrados quienes responden comprometidamente al acontecimiento en un tiempo-espacio de participación. Los eventos escénico-festivos tienen en común la ritualidad, la cual permite una reflexión que va más allá de clasificaciones estéticas porque se accede a dimensiones conviviales que se diversifican en performativas, efímeras, accionistas, participativas y políticas (Diéguez, 2014).

Al respecto, el historiador García Castro advierte que el simulacro adquiere la connotación de "manifestación de cultura cívica, popular y moderna, en constante evolución y reinterpretación de los elementos simbólicos de la historia patria mexicana" (2013: 16), es decir, no se presenta como acto ceremonioso, antes bien se expresa de manera libre y aleatoria, permite la crítica al pasado y al presente, se convierte en un espacio plural y da carta abierta a la explosión de sentimientos, saberes, experiencias, que ocurren en el conocimiento de sí mismos y los otros.

García Castro afirma que estas "celebraciones cívico-populares ya no suelen privar lo solemne, sino todo lo contrario, hay lugar aquí para la innovación, lo lúdico, lo satírico, la irreverencia social y hasta, en cierto sentido, para la protesta social" (2013: 22). Este acontecimiento, sin duda alguna, está envuelto en una dinámica compleja en donde se articula una red semántica con una fisonomía de zona de experiencias fundada en el convivio (Dubatti, 2010).
Se debe agregar que el simulacro en sí mismo cuestiona temas de orden político, de modo que adquiere un tono de resistencia y resiliencia, y crea alianzas que fortalecen el discurso artístico y la percepción del espectador. Así, presenta y representa una posibilidad de reflexión y diálogo en colectividad con el único propósito de celebrar(se), divertir(se), presentar(se), ${ }^{10}$ por lo tanto, es una experiencia de comunión con alto sentido de convivialidad, donde la presencia de imaginarios es ineludible.

La peculiar manera de adaptarse, de moverse, se reconfigura cada año, renovando formas y caracterizaciones, por ello, reafirma su relación con el contexto externo y también con el interno, pues permite nuevas alianzas entre los participantes. Aunque el motivo es único, la manera de vivenciarlo es cambiante, se acopla a las circunstancias. No obstante, hay aspectos que adquieren consistencia y permanecen. El acontecimiento es un todo que, a partir de sus componentes, genera una praxis singular por la manera de expresarse, como podemos apreciar en el cuadro 1:

\section{Cuadro 1: Simulacro y teatralidad}

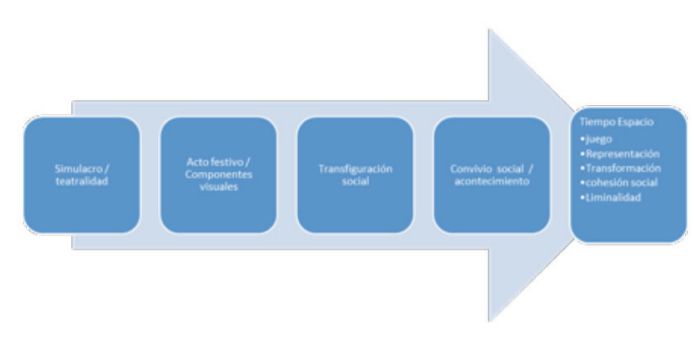

Fuente: Elaboración propia.

La sociedad que surgió tras la Independencia de México soportó los efectos, o, mejor dicho, los 'desperfectos' e inconsistencias de tal conflicto,

10 La intención de colocar los verbos en primera y tercera persona es una postura en la que situamos al participante del simulacro, toda vez que él se asume o performa en los planos observador/observado, en cualquiera de las acciones. 
mismos que derivaron en otro movimiento armado un siglo después, la Revolución mexicana. Las políticas educativas posteriores a 1910 planearon inocular entre la población el sentimiento nacionalista, generando imaginarios y prácticas socioculturales, como los desfiles cívico-militares, las verbenas y ceremonias, todos ellos con un propósito semejante. Si bien dichos actos incluían a todos los sectores de la población, los marginados, los 'nadie', sólo contemplaban la historia que la autoridad les ofrecía. A lo largo de los años, estos observadores cambiaron el plano de contemplación para situarse como observados que desafían el olvido y la anulación social, de manera que su posicionamiento representa la fuerza de su origen, conformando un espacio de libertad en el que coexisten fiesta, acontecimiento y teatralidad.

Más allá de dramatizar de manera verosímil episodios sobre la Independencia de México, el simulacro se presenta como una teatralidad intervenida por los pobladores, de manera que en él se filtran categorías de identidad, comunidad, crítica y fiesta cívico/religiosa. Por ello, el estudio de relaciones entre práctica estética y práctica sociocultural invitan a reflexionar desde tres perspectivas: la primera expone una fiesta que originalmente cumple un propósito recreativo/educativo asociado a las iniciativas del movimiento vasconcelista: ${ }^{11}$ la educación popular y el desarrollo cultural. Tales factores sostienen

11 En los albores de la Revolución mexicana, José Vasconcelos, filósofo, político y educador, generó un movimiento crítico de renovación ideológica y política para impulsar la educación indígena, rural y técnica. En su proyecto destacan las misiones culturales, instituidas bajo el pensamiento nacionalista en favor de la liberación y dignificación de la persona. En su intención de reorientar a las masas, Vasconcelos expuso, en el expediente sobre reformas al artículo 14 y a la fracción XXVII del artículo 73 de la Constitución Federal, que "el estado debe exigir del artista que trabaje en una producción artística rica y elevada que traerá consigo la regeneración y exaltación del espíritu nacional" (Pérez Montfort, 2000: 41). Por lo anterior, la identidad nacional se fundó en una construcción imaginaria con ayuda de la literatura y la música. Según Pérez Montfort, la valoración de tradiciones populares se juzgaba por élites intelectuales que determinaron la manera de expresarlas, acudiendo así a su invención hasta consolidarlas como estereotipos nacionales (2000). la hipótesis sobre el origen de los simulacros como estrategias para cumplir dicho objetivo. Un segundo enfoque los sitúa como constructos ideados por el propio Estado para 'simular' las nociones de identidad y pertenencia. La tercera mirada advierte que la celebración responde a las necesidades de convivencia y expresión cultural en aquellas localidades, con el propósito de afianzar lazos de vida en comunidad.

La teatralidad del simulacro reúne elementos de los actos festivos, así como categorías de identidad y pertenencia. Entre sus variados propósitos, genera encuentros con el juego, el gozo, el ritual, la crítica, pero también desarrolla formas explosivas, violentas y catárticas en el plano de la colectividad, como lo destacó Johan Huizinga (1984). Desde tiempos remotos, en toda civilización el juego humano, cuando significa o celebra algo, se coloca en la esfera de la fiesta o el culto, es decir, es un ámbito de libertad que también conlleva elementos sagrados.

Si bien puede analizarse su carácter caótico, nos preguntamos cómo un acto tan complejo, constituido por una diversidad de mensajes sociales, estéticos y culturales, puede funcionar sin el dispositivo del orden oficial. La respuesta posiblemente radica en el imaginario del 'juego de la guerra', pues cómo resistirse a la tentación liberadora, al hechizo de vivir lo extraordinario por breve tiempo, cobijado por el disfraz y la máscara que permiten actuar como otro.

En el terreno social, el juego sirve para el bienestar del grupo, por eso el simulacro se aparta de la vida corriente, para limpiar, depurar y hacer a un lado el cansancio de lo rutinario. Se puede hablar de una renovación de ciclo en demarcación del tiempo-espacio festivo, patente en un ir y venir de lo ficticio a lo real, que también podría llamarse efecto de 'reversibilidad', es decir, se trata de ver las cosas desde distintas posiciones mediante un pensamiento bidireccional. Sin embargo, cuando la reversibilidad se agota, sólo permanece en el recuerdo para situarse como tesoro espiritual (Huizinga, 1984). Así, 
con el juego de la guerra de Independencia nace el imaginario de la libertad en posesión exclusiva de los participantes y espectadores.

Además de ser una fiesta, el simulacro se sitúa en la frontera entre teatralidad y liminalidad, ${ }^{12}$ lo que nos hace preguntarnos si lo que se contempla es teatro o la vida misma. Aun cuando se conservan características del convivio y de la necesidad esencial del hombre por reunirse, asoma también el término 'práctica social', propuesto por Víctor Turner para referir "un tiempo y lugar de alejamiento de los procedimientos normales de la acción social" (1988: 171). Por lo anterior, este acontecimiento festivo se aventura al encuentro de la purificación, la transformación de lo cotidiano y la recuperación del curso de la vida.

En la serie de actos que estructuran el simulacro-teatralidad, la hibridación de discursos adquiere formas sincréticas espaciotemporales en donde el pasado se hace presente a partir de la inclusión de nuevos elementos, hay crítica permanente, los conflictos entre los participantes aparecen y desaparecen de maneras simultáneas, y se declara un cruce de tiempos que representan la realidad, permitiendo que se territorialicen y desterritorialicen las acciones. En ese complejo de contradicciones aparece la liminalidad.

Más allá de la espectacularidad, se vislumbra un detrás del espejo que nos permite sondear otra dimensión más allá de lo aceptado por los sentidos, dado que el hecho 'simula' funcionar como instrumento político. Si bien originalmente surgieron con un propósito recreativo/educativo a modo de procedimiento estratégico, para Michel De Certeau (1996) estas maneras de hacer

12 'Liminalidad' refiere los fenómenos histriónicos, tanto del pasado como de la actualidad, que no encuadran en el marco de un teatro convencional o dramático (representación de una historia con trama, personajes, ficción). La aplicación de esta noción pone en duda si lo que se contempla es teatro, pues engloba la idea de combinación, fusión o conflicto, tránsito, circulación y cruce, puente y prohibición, permanencia o intermitencia, zona de mezcla, hibridez y transfiguración (Dubatti, 2010). cotidianas aquellas representaciones y comportamientos de la sociedad sometidas a categorías de consumo-producción hacen suponer que el 'simulacro' es, más que un acto de lo cotidiano, una representación y comportamiento para ser extraño en lo suyo.

Para los pobladores de esas localidades, la celebración de la Independencia es un acontecimiento que nace y se desarrolla en el plano más genuino de la sociedad, el pueblo, "al insistir en la teatralidad como práctica, remarco su condición de suceso, de actividad inserta en el tejido de los acontecimientos de la esfera vital y social" (Diéguez, 2014: 18). Estamos ante una actividad que se interioriza desde el vientre, pues los miembros más pequeños, bebés o niños de brazos, se inician en el rito gracias a sus padres, formando parte de la tropa como españoles, apaches, costeños o guarines, de esta manera se va inculcando y preservando el festejo, dado que los progenitores así lo aprendieron también.

De esto se desprende que la tradición se manifiesta como una necesidad, pero que se ejerce al mismo tiempo que la modernidad, sin presentar contradicciones, antes bien coexisten en igual tiempo y espacio representacional. Esta combinación híbrida de realidades y mundos experienciales es refrendada por el simulacro cada año, de manera cíclica, pero cambiante.

Sea el 15 y 16 de septiembre en Ixtapan, o el 26 y 27 en Tonatico, se hace un alto a la cotidianidad. Mientras que la fiesta institucionalizada se apoya en procedimientos de operación y manipulación para aplicar el poder con reglas explícitas, esta táctica se convierte en estrategia ante la respuesta pragmática de la comunidad al apropiarse del fenómeno. En el simulacro, quien interpreta no ve el entorno de manera ordinaria, dada la dimensión que le asigna el carácter representado. En él se hacen visibles cosas, objetos o situaciones altamente reveladoras para quien se permite ser tocado por esa mirada y acepta un intercambio de experiencias y sentimientos de manera exaltada, pero franca. 
La máscara en el simulacro, más allá del tratamiento escénico, tiene una connotación socio-antropológica porque atañe a aspectos de pertenencia y comportamiento cotidiano de los participantes en comunidad. El maquillaje, entonces, funciona como una máscara social flexible que representa el concepto que cada individuo ha creado, transfigurándolo a él mismo y al personaje que desearía ser: héroe de la Independencia, apache venerable, costeño aguerrido e inmortal, español vencedor, guarín admirado y popular. La trasfiguración referida aparece en tres esferas: el rol social establecido, los elementos de trasfondo escénico y las representaciones sociales. La reunión de estos ámbitos modifica el comportamiento social del individuo, el cual se dirige a una auténtica expresión de su personalidad al tomar prestado otro carácter para entrar en un juego de representación de roles o máscaras.

Los imaginarios que produce el simulacro tienen el potencial de reinventarse porque representan la forma más pura de la sensibilidad, diversifican narrativas del cuerpo, posibilitan la verbalización de emociones y, sin planearlo, tiempo-espacio dan cabida al universo de lo que ya no es, pero que, involuntariamente, conforma un territorio de creencia de lo que todavía no es.

Como bien afirma Jean-Luc Nancy (2013), el simulacro consiste en diferenciar lo vidente y lo visible, ver a través de una mirada no sólo lo que los ojos pueden informar. ¿Por qué hablamos de otra mirada? Huberman (2015) diría que mirar constituye un estado de introspección y toma de conciencia, pero al mismo tiempo es un punto en el que el sujeto se reproduce en el infinito de la obra: la mise en abyme sitúa al participante en una perspectiva sin fin, estado que puede ser altamente inquietante o perturbador, por lo tanto, revela lo más oculto y primigenio del hombre. Así, la mirada funciona como recurso para abismar el simulacro en un acto performativo, en una obra dentro de otra. El fenómeno manifiesta una realidad en segundo grado para inscribirse en una dimensión liquida donde las ideas, el pensamiento, las emociones se fusionan (Imagen 10).

\section{Imagen 10. Gallinero, Tonatico}

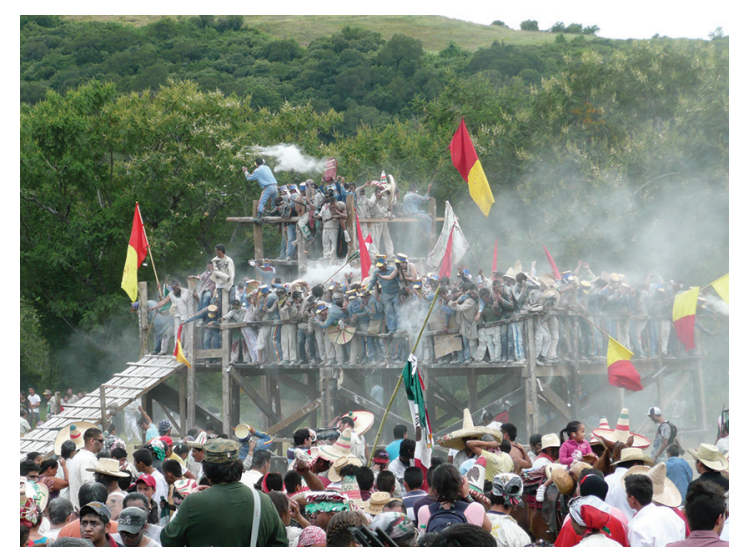

Fotografía: Alejandro Flores Solís (2012).

Trascender esta teatralidad sólo sería posible mediante una inmersión desinteresada en un acto multitudinario que reúne a poco más de cuatro mil participantes, quienes bailan y gritan desde las puertas de sus casas las consignas 'viva México', 'viva Ixtapan', 'vivan los apaches', 'viva Tonatico'. Los pobladores beben y desbordan frenesí para transfigurarse cantando estribillos como:
México guadalupano
$\mathrm{y}$ tu bandera tricolor
la tradición del pueblo
nunca se podrá olvidar
esperemos que a los nuevos
no se les vaya a olvidar ${ }^{13}$

El simulacro hace surgir nuevas maneras de apreciar tanto la vida en colectividad como las formas de organización a partir de algo en común, pese a las imperfecciones. El imaginario en torno a la Independencia adosa más a una dependencia

13 Trabajo de campo, 2019. 
encubierta en el color, la euforia y la 'alegría aplastada', como la nombró Roger Bartra en su texto La jaula de la melancolía (2002). Con la creación de tipos o roles, los participantes juegan escénicamente a ser héroes, hombres valientes, tan explosivos y efímeros como las detonaciones de sus mosquetes. Lo anterior deriva en imágenes y situaciones del tipo /valentía-afirmación/ / mírame-hoy existo/ /tricolor-México-libre/ /jodidamente-alegre/ /ser -sin ser/ (Imagen 11).

\section{Imagen 11. Fusilamiento de Hidalgo}

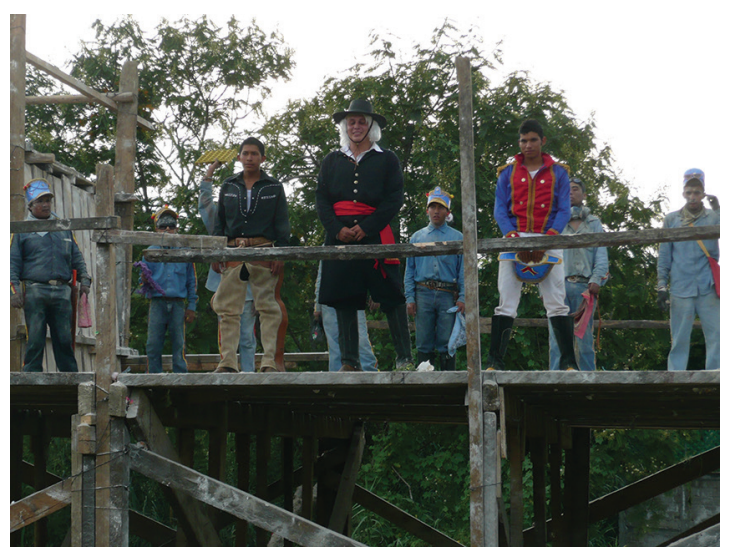

Fotografía: Alejandro Flores Solís (2012).

La dinámica del acontecimiento se manifiesta en su modo nuclear o matriz, que es la teatralidad, para concebir formas de participación, cumpliéndose así la máxima en el proceso creativo del simulacro: la intervención activa de todos los actores sociales para performar la convivencia.

Desde la mirada de Žižek, acontecimiento también es caída, "la pérdida de una unidad y armonía primordiales que nunca existieron, que no son más que una ilusión retroactiva” (2014: 53). ¿Qué recurso más eficaz para superar la inminente catástrofe de la independencia fallida que el simulacro? Se crea entonces un dispositivo para dar cuenta del ilusorio triunfo y, pese a ello, situarse del lado de los vencedores. En este sentido, el simulacro opta por la libertad interpretativa del hecho, recreando batallas en el plano escénico que le permiten explicar la significación histórica de la Independencia de México.
Al término de la fiesta, la cotidianidad se recupera, escuelas, comercios y oficinas vuelven a sus actividades. No hay enojo ni delito por el caos del día anterior, todos saben que es parte del juego, viven la purificación que sobreviene a la catarsis y la satisfacción de haber participado un año más en este evento. Mediante el cuerpo, el color, el disfraz y la euforia desbordante, los pobladores se miran representados en el límite, más allá de la fiesta. Este ejercicio simbólico en verdad representa la batalla de nuestra memoria, identidad y conciencia reunidas para la cimentación del imaginario sobre la independencia, un acontecimiento capaz de afianzar estructuras para la convivencia e interrelación dinámica, tan necesarias para resguardar la teatralidad latinoamericana.

\section{AcTO FINAL: REFLEXIONES}

La teatralidad del simulacro le permite a cada participante explorar su percepción del hecho histórico. Mediante la representación se vislumbra una potencia creadora de imaginarios a partir de la propia cotidianidad. El baile, la música, las detonaciones de pólvora son insumos para desarrollar una embriaguez de los sentidos y constituyen la fórmula para la fascinación que sostiene al fenómeno, aun cuando se aleja de los valores ideales de una sociedad. Asimismo, tiene una naturaleza acontecimental en todas sus perspectivas, porque revive la historia y narra desde el presente las incertidumbres y esperanzas que simboliza la Independencia.

Si bien existen investigaciones que abordan los simulacros, poseen enfoques distintos a la presente disertación. Sin embargo, reconocemos la valía de los estudios que nos anteceden porque destacan elementos sobre las fiestas cívico populares, la reconstrucción de hechos históricos, la conexión con el fenómeno migratorio en aquellas poblaciones, la revaloración de la cultura 
popular, el desarrollo socioeconómico que genera la celebración, las dinámicas de sistemas de creencias y, en consecuencia, la aparición de sincretismos particulares.

Estos antecedentes han permitido profundizar en el conocimiento sobre las poblaciones, los sujetos o actores sociales que los protagonizan y la diversidad de contextos en los que se articula la festividad. El objetivo central radicó en examinar dichos componentes desde la perspectiva de las teatralidades para concluir que el simulacro es una cadena de actos representacionales, incluso performativos.

La inclusión de la comunidad en cada fase o proceso del simulacro es, sin duda alguna, fundamental, así como la suma de una diversidad de actividades sociales, comerciales y culturales en donde convergen acciones-ficciones, presentaciones y representaciones sociohistóricas en las que se inserta el acontecimiento del convivio.

Como bien afirma Dubatti, el convivio, además de necesitar que se reúnan los sujetos en un lugar determinado, pone en juego un "encuentro de presencias en el espacio y convivencia" (2007) que articulan procesos comunicativos en donde los cuerpos se conectan, los discursos se pronuncian de manera coordinada y se reestructuran los procesos identitarios, de modo que el 'yo' y los 'otros' coincidan colectivamente.

El simulacro también constituye una explosión de los sentidos, una experiencia sensorial y afectiva que se reconfigura incesantemente desde los imaginarios que aparecen de manera diversificada y no como arquetipos primigenios. Dichos imaginarios inciden en el contexto donde se insertan los simulacros y delimitan el conjunto de representaciones socioculturales en relación con las representaciones sociales para acotar el espectro de los procesos de interacción entre la comunidad y sus miembros.

Aunque cada año se realiza la festividad, siempre sorprende la inclusión de nuevos elementos y la reconfiguración de otros, además, resulta valioso reconocer la permanencia de aquellos que otorgan identidad a los contingentes y participantes. Sin duda, estamos frente a un conjunto de procesos de socialización que requieren del convivio (Dubatti 2007) y permiten advertir cómo las comunidades integran y crean actos, acciones, convivencias, desde las cuales organizan formas de pensar, festejar y generar distintas experiencias de vida (García Castro, 2013).

Así, el simulacro se erige como un acontecimiento creado en, por y para la comunidad, que permite abrir espacios de convivencia, intercambio, protesta, confrontación con lo establecido, con el olvido, con la dependencia/independencia. La apropiación y reapropiación que los pobladores han hecho de este acto es semejante a la revuelta representada. Su naturaleza violenta, tosca, abrupta - pese a toda creencia- genera un espacio de paz y justicia tras el conflicto porque los protagonistas visualizan y reconfiguran su realidad en el intervalo espaciotemporal de libertad que el teatro les provee, ipuede haber algo más justo y libre?

\section{REFERENCIAS}

Alatriste Tobilla, Janitzio, Eduardo Bernal Gómez, Manuel Encastin Cruz (2010), "El arte como posible conocimiento", Espacios Públicos, vol. 13, núm. 29, pp. 158-174.

Alcántara Mejía, José Ramón (2002), Teatralidad y cultura. Hacia una estética de la representación, México, Universidad Iberoamericana.

Arana Grajales, Thamer (2007), "El concepto de teatralidad", Artes. La Revista, núm.13, vol. 7, pp. 79-89.

Arizmendi Domínguez, Luis René (1999), Ixtapan de la Sal. Monografía municipal, Toluca, Instituto Mexiquense de Cultura/Asociación Mexiquense de Cronistas Municipales.

Bartra, Roger (2002), La jaula de la melancolía, México, CONACULTA.

De Certeau, Michel (1996), La invención de lo cotidiano. I. Artes de hacer, México, Universidad Iberoamericana/Instituto Tecnológico y de Estudios Superiores de Occidente.

Didi-Huberman, Georges (2015), Fasmas. Ensayos sobre la aparición 1, Santander, Contracampo Libros.

Diéguez, Ileana (2014), Escenarios liminales. Teatralidades, performatividades, políticas, México, Gobierno del Estado de Querétaro/Paso de Gato/Gobierno del Estado de San Luís Potosí. 
Dubatti, Jorge (2007), Filosofía del teatro I. Convivio, experiencia, subjetividad, Buenos Aires, Atuel.

Dubatti, Jorge (2010), Filosofía del teatro II. Cuerpo poético y función ontológica, Buenos Aires, Atuel.

Flores Solís, Alejandro (2016), Las danzas de conquista. Un encuentro con la teatralidad, Toluca, UAEM.

García Canclini, Néstor (1994), Las culturas populares en el capitalismo, México, Nueva Imagen.

García Castro, René (2013), "Participación popular y protesta social en el simulacro de Guerra de Independencia en Tonatico, Estado de México", Contribuciones desde Coatepec, año XIII, núm. 25, pp. 15-39.

Huizinga, Johan (1984), Homo ludens, Madrid, Alianza Emecé.

Nancy, Jean-Luc (2013), El peso de un pensamiento, Castellón, Ellago Ediciones.

Pérez Domínguez, Érika (2011), "La independencia de Méxi$\mathrm{co}$, un festejo transnacional en Tonatico, Estado de México", en Lourdes Arizpe, (coord.) (2011), El patrimonio cultural cívico. La memoria política como capital social, México, Porrúa, pp. 89-101.

Pérez Montfort, Ricardo (2000), Avatares del nacionalismo cultural. Cinco ensayos, México, CIESAS.

Sandoval Forero, Eduardo Andrés y Carlos Nazario Mora Duro (2010), "El caso de estudio: Tonatico, Estado de México", en Migrantes e indígenas: acceso a la información en comunidades virtuales interculturales, México, UAEM/ UAIM, pp. 51-131.

Tovar, Juan (2006), Doble vista. Teoría y práctica del drama, México, El Milagro/CONACULTA.

Turner, Víctor W. (1988), El proceso ritual, Madrid, Taurus.

Vázquez Illana, Oscar Prisciliano (1992b), "El Simulacro. Datos, anécdotas, discursos, cantos y comentarios sobre esta gran fiesta. Primera parte”, en Tonatico [folleto], núm. 12.

Vázquez Illana, Oscar Prisciliano (1992a), Monografía municipal de Tonatico. Región IV, Toluca, Gobierno del Estado de México.

Žižek, Slavoj (2014), Acontecimiento, Madrid, Sexto Piso. 


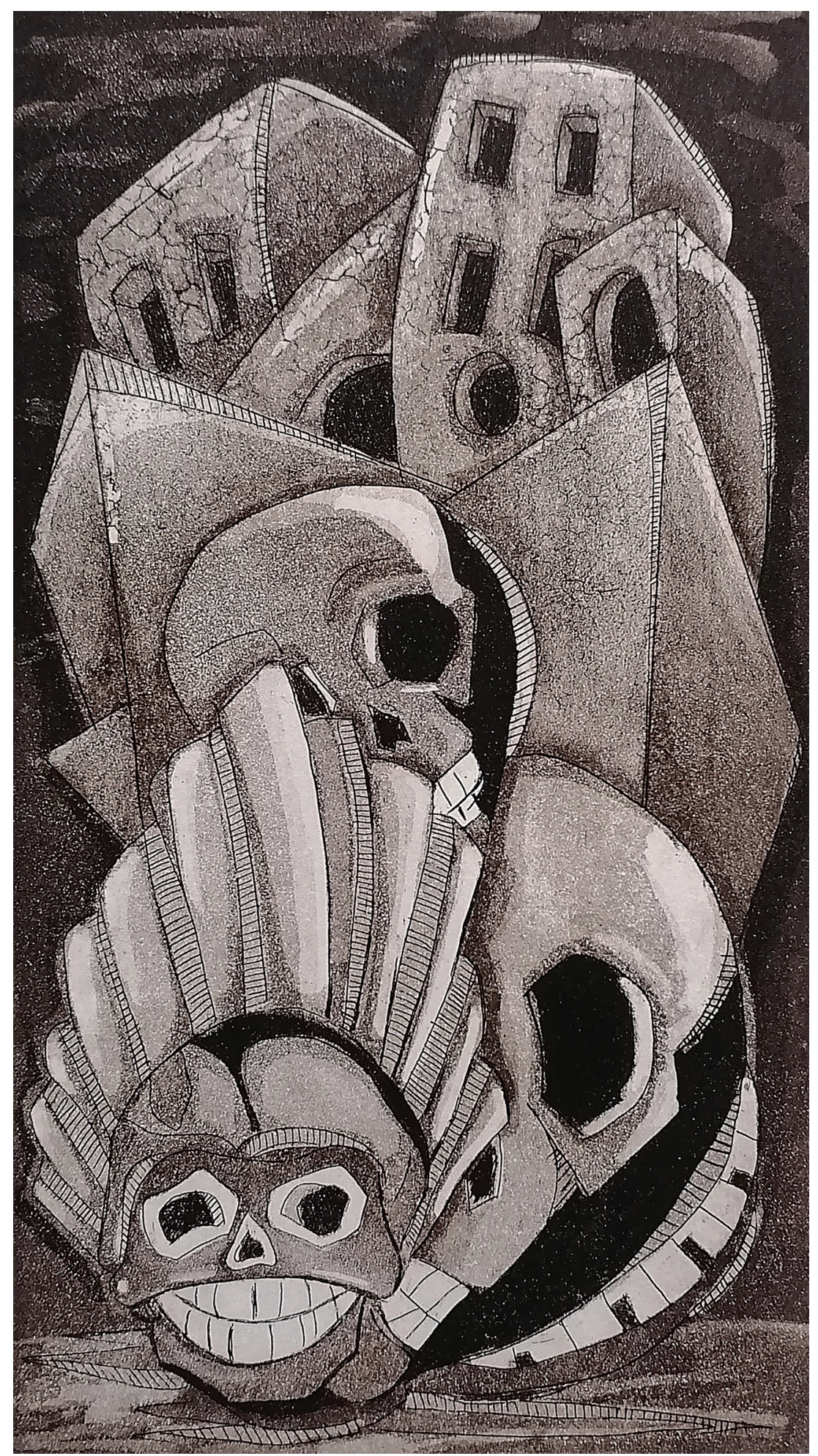

Delirios de una agonia prolongada (s/f ). Colografía: Juan Manuel Martínez Jaramillo. Prohibida su reproducción en obras derivadas. 